\title{
Effect of Intravenous Sildenafil on Pulmonary Hemodynamics and Gas Exchange in the Presence and Absence of Acute Lung Injury in Piglets
}

\author{
PIA K. RYHAMMER, LARA S. SHEKERDEMIAN, DANIEL J. PENNY, AND HANNE B. RAVN
}

Department of Anesthesia and Intensive Care and Institute of Experimental Clinical Research [P.K.R., H.B.R.], Aarhus University Hospital, 8200 Aarhus N, Denmark; Paediatric Intensive Care Unit [L.S.S.], and Cardiology Department [D.J.P], Royal Children's Hospital, Parkville, Victoria 3052, Australia

\begin{abstract}
Sildenafil is becoming increasingly popular for the treatment of pulmonary hypertension. However, there are potential concerns regarding its effects on oxygenation and systemic hemodynamics that could theoretically reduce its utility in the neonatal population. We performed a prospective cumulative dose-response study of increasing doses of i.v. sildenafil $(0.4,1$, and $3 \mathrm{mg} / \mathrm{kg})$ on hemodynamics and oxygenation in 32 anesthetized piglets, of which 17 had meconium-induced pulmonary hypertension and lung injury, and 15 did not. Sildenafil caused a reduction in mean pulmonary artery pressure and pulmonary vascular resistance (PVR) at all doses, in non-lung-injured animals. There was no difference in pulmonary hemodynamics between doses. Oxygenation index [OI $=$ mean airway pressure $\left.\left(\mathrm{cm} \mathrm{H}_{2} \mathrm{O}\right) * \mathrm{FiO}_{2} * 100 / \mathrm{PaO}_{2}(\mathrm{~mm} \mathrm{Hg})\right]$ did not reach critical levels at any dose. In lung-injured animals, sildenafil also reduced mean pulmonary artery pressure and PVR by $30 \%$. Again, this effect was achieved at the lowest dose, without subsequent changes at higher doses. However, in lung-injured animals, sildenafil produced a dose-related increase in oxygenation index. Sildenafil reduced the systemic vascular resistance (SVR) at the lowest dose in lung-injured animals, but this occurred only at higher doses in non-lung-injured animals. In conclusion, sildenafil is a potent pulmonary vasodilator. However, it should be administered with caution in the presence of lung injury because of a dose-related increase in oxygenation index and concomitant systemic vasodilatation. (Pediatr Res 59: 762-766, 2006)
\end{abstract}

$\mathrm{P}$ ersistent pulmonary hypertension of the newborn (PPHN) is a significant cause of morbidity and mortality in neonates $(1,2)$. Meconium aspiration syndrome is the single most common cause of PPHN in term infants. Around 5\% of newborns aspirate meconium and develop a degree of lung injury (3). This parenchymal lung injury can, when severe, lead to PPHN with severe cardiopulmonary impairment and hypoxemia.

Current treatment of PPHN includes therapies aiming at reducing the PVR, including nitric oxide [augmenting cyclicguanosine $5^{\prime}$-monophosphate (cGMP)], prostacyclin [aug-

Received September 28, 2005; accepted January 18, 2006.

Correspondence: Hanne B. Ravn, M.D., Ph.D., Department of Anesthesia and Intensive Care, Skejby Sygehus, Brendstrupgårdsvej, 8200 Aarhus N, Denmark; e-mail: hbr@ki.au.dk.

This research was supported with grants from the Laerdal Foundation and The University of Aarhus, Denmark.

DOI: 10.1203/01.pdr.0000219501.58546.aa menting cyclic-adenosine 5'-monophosphate (cAMP)], and dipyridamole [phophodiesterase-5 (PDE-5) inhibitor delaying degradation of cGMP]. More recently, another PDE-5 inhibitor sildenafil (Viagra) has gained increasing interest in the treatment of pulmonary hypertension (4-9). Sildenafil is eliminated primarily by hepatic metabolism (mainly cytochrome P-450 3A4) and is converted to an active metabolite with similar properties. Both forms have a half-life of approximately $4 \mathrm{~h}$. Enterally administered, sildenafil has been shown to reduce pulmonary arterial pressure without impairing systemic hemodynamics in hypoxia-induced pulmonary hypertension (10). When administered by the enteral route, the bioavailability is only about $40 \%$ in healthy individuals (11). In the critically ill neonate, absorption from the gut may be even more unpredictable.

We have previously shown that i.v. sildenafil is able to reduce PVR both when given alone and in combination with nitric oxide $(12,13)$. However, when given in combination with nitric oxide, the OI [OI = mean airway pressure $(\mathrm{cm}$ $\left.\left.\mathrm{H}_{2} \mathrm{O}\right) * \mathrm{FiO}_{2} * 100 / \mathrm{PaO}_{2}(\mathrm{~mm} \mathrm{Hg})\right]$ increased significantly. This observation was in keeping with the findings of Kleinsasser et al. (14), who observed systemic vasodilatation and an increase in intrapulmonary shunt in animals receiving enteral sildenafil.

The purpose of this study was twofold. First, we wished to establish whether the adverse effects of sildenafil on systemic hemodynamics and oxygenation were dose related, and second we investigated whether these effects occurred only in the presence of lung injury.

\section{MATERIALS AND METHODS}

The study was approved by the National Board on Animal Care and Use. Thirty-two Danish Landrace piglets (mean weight $4.9 \mathrm{~kg}$ ) were premedicated with an intramuscular injection of ketamine $(10 \mathrm{mg} / \mathrm{kg})$ and midazolam $(0.5 \mathrm{mg} / \mathrm{kg})$. The animals were subsequently ventilated, and instrumented for the study as previously described (12). A stable plane of anesthesia was

Abbreviations: OI, oxygenation index; PPHN, persistent pulmonary hypertension of the newborn; PVR, pulmonary vascular resistance; SVR, systemic vascular resistance- 
maintained through the experiment with an i.v. infusion of fentanyl (60 $\mu \mathrm{g} / \mathrm{kg} / \mathrm{h})$ and midazolam $(6 \mathrm{mg} / \mathrm{kg} / \mathrm{h})$.

Systemic blood pressure, pulmonary arterial pressure and central venous pressure were continuously monitored and cardiac output was measured in triplicate using thermodilution. Hemodynamic and ventilatory measurements were recorded every $60 \mathrm{~min}$.

After completing the preparation, hemodynamics were allowed to stabilize for $30 \mathrm{~min}$ and then blood gas analysis was performed, hemodynamic and ventilatory variables were recorded and cardiac output was measured. Ventilation was subsequently adjusted to achieve a $\mathrm{Po}_{2}$ of $70-110 \mathrm{~mm} \mathrm{Hg}$, and $\mathrm{PCO}_{2}$ of $35-45 \mathrm{~mm} \mathrm{Hg}$, and $30 \mathrm{~min}$ later, all recordings were repeated. This set of measurements was taken as baseline $(0 \mathrm{~min})$. Systemic and pulmonary vascular resistance and oxygenation index were calculated using standard equations.

The animals were assigned to one of four groups, as shown in the flow chart (Fig. 1). Seven animals remained anaesthetized and received no further therapeutic interventions. Eight animals received hourly, incrementally increasing, doses of i.v. sildenafil $(0.4 \mathrm{mg} / \mathrm{kg}, 1 \mathrm{mg} / \mathrm{kg}$, and $3 \mathrm{mg} / \mathrm{kg}$, respectively) following baseline measurements. Ten had endotracheal instillation of meconium with no other therapeutic interventions. The remaining seven animals received an endotracheal instillation of meconium (as previously described) after baseline measurements (12), followed by three incrementally increasing doses of sildenafil, as above, starting at $120 \mathrm{~min}$, as hemodynamics previously were shown to reach a plateau at this time $(12,13)$. In all animals, hemodynamic measurements, blood gases, and ventilatory settings were recorded every $60 \mathrm{~min}$. Ventilation was adjusted to achieve the target blood gases, where possible. At the end of the study period, the animals were killed with an overdose of pentobarbital (1000 mg/kg).

Sildenafil preparation. Sildenafil was infused over $30 \mathrm{~min}$ as a solution of sildenafil citrate $1 \mathrm{mg} / \mathrm{mL}$, diluted in isotonic $\mathrm{NaCl}$ to a total volume of 15 $\mathrm{mL}$. For ease of interpretation, we have referred to the incremental doses of sildenafil of $0.4 \mathrm{mg} / \mathrm{kg}, 1 \mathrm{mg} / \mathrm{kg}$, and $3 \mathrm{mg} / \mathrm{kg}$ as low, medium, and high dose, respectively.

Statistics. The hemodynamic parameters were analyzed by repeatedmeasure analysis to compare the two or three groups with respect to change over time. The data were analyzed on a logarithmic scale using SPSS statistical package version 10.0.5. In the figures, the geometric mean values are shown for each group at each time point. The geometric means are calculated from the mean on the logarithmic scale and are an estimate of the median.

Changes over time (Table 1) are stated as mean relative changes with 95\% confidence interval. No error bars are shown in the figures, but the coefficient of variation (on the original scale), which is approximately the SD on the (natural) logarithmic scale is presented in parentheses in the tables.

A $p$ value $<0.05$ was considered statistically significant.

\section{RESULTS}

There was no difference in weight, systemic and pulmonary hemodynamics, or blood gases at baseline between groups.

Effect of i.v. sildenafil in the absence of lung injury. Intravenous sildenafil reduced pulmonary artery pressure (PAP) $(p=0.003)$ and PVR $(p=0.01)$ over time when compared with baseline (Fig. 2). PVR was significantly reduced by $29 \%$ in comparison with the control animals that were only anesthetized $(p=0.03)$. This effect was present at the lowest dose of sildenafil and was not further augmented

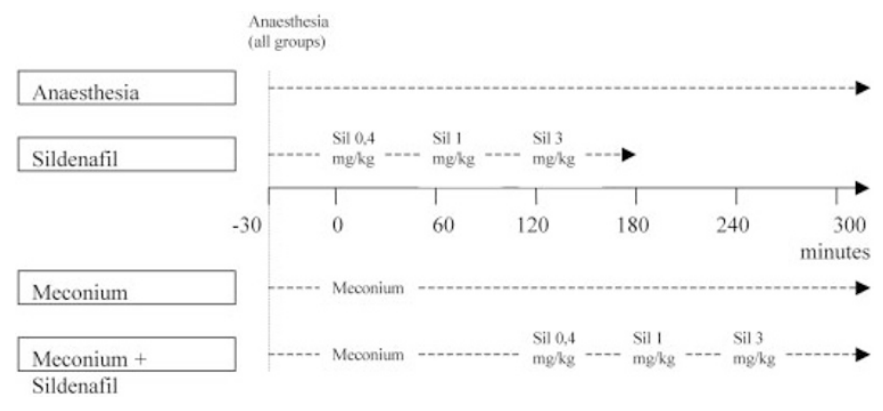

Figure 1. Flow chart represents interventions in the four groups of animals. Sil, sildenafil infusion. with increased doses. The sildenafil infusion did not alter mean arterial pressure significantly in comparison to baseline, but compared with the anesthesia controls, systemic blood pressure was significantly reduced in animals receiving sildenafil alone $(p=0.006)$ (Fig. 3). SVR decreased by $21 \%$ ( $p=$ 0.02 ), but cardiac output remained unchanged during sildenafil infusion.

A significant increase in OI was found $(p<0.001)$, but the relatively stable values with OI $<5$ indicate that the worsening in lung oxygenation was not clinically significant (Fig. 2).

Effect of i.v. sildenafil in animals with meconium aspiration. Instillation of meconium caused a significant increase in PAP (Fig. 2). The lowest dose of sildenafil caused a $32 \%$ reduction in PAP $(p=0.001)$, whereas increasing doses did not augment the effect. Following the first dose of sildenafil, the PVR went down by $68 \%$ to baseline values $(p<0.001)$. The first two doses of sildenafil did not change mean arterial pressure significantly, but following the highest dose, a marked fall in blood pressure was observed $(p=0.04)$ compared with preinfusion values (Fig. 3). SVR was significantly reduced $(p=0.03)$ following the first dose of sildenafil, while cardiac output increased $(p=0.03)$ significantly.

Instillation of meconium significantly increased the $\mathrm{OI}$ in both groups by more than $100 \%$.

OI increased by $26 \%$ ( $p=0.06$ ) following the first dose of sildenafil (Fig. 2), and the two additional doses caused statistically significant increases by $21 \%(p=0.04)$ and $31 \%(p=$ $0.001)$, respectively.

\section{DISCUSSION}

This study has demonstrated that at doses lower than previously used, i.v. sildenafil is an effective pulmonary vasodilator in pigs with acute lung injury and pulmonary hypertension secondary to meconium aspiration. We have also demonstrated for the first time similar pulmonary vascular effects of the i.v. agent in healthy, noninjured lungs. Importantly, the degree of pulmonary vasodilatation produced by sildenafil was not dose related.

Intravenous sildenafil produced a dose-dependent decrease in SVR in all animals, confirming a degree of nonselectivity for the pulmonary vasculature.

Finally, in contrast with our previous studies, in which a consistent single dose of sildenafil was used, we have now demonstrated that sildenafil produces a dose-dependent worsening in arterial oxygenation (and increase in OI), in the presence and absence of lung injury.

Timing of the sildenafil administration was based on the experience from previous studies using this model with meconium aspiration $(12,13)$, where we found that the PAP reached a plateau $120 \mathrm{~min}$ after meconium instillation and remained stable for the rest of the study period, consistent with the observations in the present study.

In a previous study (13), the OI increased significantly, when sildenafil was infused at a rate of $1 \mathrm{mg} / \mathrm{kg} / \mathrm{h}$ in animals following inhaled nitric oxide. We therefore decided to investigate whether the increase in OI was related to the actual dose given or whether it was associated with the underlying paren- 
Table 1. Mean artery pressure, pulmonary hemodynamics, and ventilatory requirements in the four groups

\begin{tabular}{|c|c|c|c|c|c|c|c|}
\hline & 0 Min & 60 Min & 120 Min & 180 Min & 240 Min & 300 Min & $p$ \\
\hline \multicolumn{8}{|l|}{ MAP/time } \\
\hline Anesthesia $(n=7)$ & $74.3(0.22)$ & $78.5(0.17)$ & $74.9(0.18)$ & $66.2(0.16)$ & $63.3(0.17)$ & $61.7(0.19)$ & 0.001 \\
\hline Sildenafil $(n=8)$ & $73.0(0.21)$ & $68.0(0.32)$ & $64.4(0.26)$ & $64.9(0.25)$ & & & NS \\
\hline $\operatorname{Mec}+\operatorname{sil}(n=7)$ & $70.8(0.18)$ & $72.8(0.11)$ & $68.1(0.11)$ & $63.1(0.23)$ & $64.6(0.16)$ & $61.0(0.15)$ & NS \\
\hline \multicolumn{8}{|l|}{ PAP/time } \\
\hline Anesthesia $(n=7)$ & $19.4(0.24)$ & $21.2(0.30)$ & $22.8(0.21)$ & $20.5(0.15)$ & $20.7(0.17)$ & $19.1(0.17)$ & NS \\
\hline $\operatorname{Mec}+\operatorname{sil}(n=7)$ & $17.4(0.15)$ & $22.3(0.14)$ & $27.5(0.24)$ & $20.0(0.14)$ & $18.8(0.05)$ & $18.4(0.06)$ & $<0.001$ \\
\hline \multicolumn{8}{|l|}{$\mathrm{Fio}_{2} /$ time } \\
\hline Anesthesia $(n=7)$ & $0.47(0.03)$ & $0.46(0.05)$ & $0.46(0.04)$ & $0.46(0.04)$ & $0.46(0.15)$ & $0.46(0.15)$ & NS \\
\hline Sildenafil $(n=8)$ & $0.48(0.05)$ & $0.48(0.06)$ & $0.49(0.07)$ & $0.49(0.05)$ & & & 0.04 \\
\hline $\operatorname{Meconium}(n=10)$ & $0.34(0.13)$ & $0.36(0.12)$ & $0.38(0.11)$ & $0.38(0.11)$ & $0.40(0.14)$ & $0.40(0.21)$ & 0.004 \\
\hline $\operatorname{Mec}+\operatorname{sil}(n=7)$ & $0.48(0.03)$ & $0.48(0.04)$ & $0.47(0.05)$ & $0.48(0.07)$ & $0.50(0.03)$ & $0.49(0.03)$ & NS \\
\hline $\operatorname{Mec}+\operatorname{sil}(n=7)$ & $14.5(0.31)$ & $13.1(0.46)$ & $11.0(0.22)$ & $9.8(0.37)$ & $8.6(0.23)$ & $7.7(0.28)$ & $<0.001$ \\
\hline \multicolumn{8}{|l|}{ PVR/time } \\
\hline Anesthesia $(n=7)$ & $0.057(0.54)$ & $0.082(0.48)$ & $0.097(0.51)$ & $0.085(0.38)$ & $0.100(0.23)$ & $0.082(0.38)$ & 0.011 \\
\hline Sildenafil $(n=8)$ & $0.063(0.42)$ & $0.047(0.40)$ & $0.047(0.35)$ & $0.044(0.39)$ & & & 0.011 \\
\hline $\operatorname{Meconium}(n=10)$ & $0.064(0.36)$ & $0.090(0.41)$ & $0.113(0.43)$ & $0.130(0.31)$ & $0.127(0.37)$ & $0.129(0.40)$ & $<0.001$ \\
\hline $\operatorname{Mec}+\operatorname{sil}(n=7)$ & $0.045(0.44)$ & $0.077(0.35)$ & $0.110(0.33)$ & $0.056(0.32)$ & $0.050(0.38)$ & $0.047(0.48)$ & $<0.001$ \\
\hline \multicolumn{8}{|l|}{ OI/time } \\
\hline Anesthesia $(n=7)$ & $3.2(0.56)$ & $3.4(0.48)$ & $3.3(0.22)$ & $2.9(0.21)$ & $3.2(0.32)$ & $3.2(0.21)$ & NS \\
\hline Sildenafil $(n=8)$ & $2.2(0.22)$ & $2.3(0.21)$ & $2.6(0.20)$ & $2.8(0.24)$ & & & $<0.001$ \\
\hline $\operatorname{Meconium}(n=10)$ & $3.1(0.32)$ & $8.8(0.34)$ & $7.2(0.37)$ & $7.3(0.41)$ & $8.0(0.60)$ & $7.4(0.49)$ & $<0.001$ \\
\hline $\operatorname{Mec}+\operatorname{sil}(n=7)$ & $2.1(0.31)$ & $7.3(0.51)$ & $8.1(0.68)$ & $10.5(0.88)$ & $13.1(0.83)$ & $17.8(0.76)$ & $<0.001$ \\
\hline
\end{tabular}

Data are given as geometric means and the numbers in parentheses are coefficients of variation.

$p$ Values reflect changes over time.

NS, not significant; MAP, mean aortic pressure $(\mathrm{mm} \mathrm{Hg})$; PAP, pulmonary artery pressure $(\mathrm{mm} \mathrm{Hg}) ; \mathrm{FiO}_{2}$, inspiratory fraction of oxygen; $\mathrm{PaO}{ }_{2}$, partial pressure of oxygen in arterial blood.

chymal lung injury during the course of meconium aspiration. For that purpose, we chose the same dose as previously and compared the effect with a lower and a higher dose, respectively. Even the lowest dose was sufficient to reduce PAP and PVR to baseline values, and higher doses did not cause any significant changes. In contrast, the OI increased with increasing doses of sildenafil, which is likely to reflect a dosedependent adverse effect of the drug. However, we cannot completely rule out that it may partly be time dependent as well, although the OI remained stable in the meconium control animals.

Kleinsasser et al. (14) compared three doses of enteral sildenafil with healthy anesthetized pigs without lung injury and, like us, found significant reductions of PAP, PVR at all doses, and dose-dependent effects on systemic hemodynamics, oxygenation, and intrapulmonary shunt.

The exaggerated detrimental effect on oxygenation of sildenafil in animals with meconium aspiration in our current study, when compared with the healthy controls, would confirm more profound effects on intrapulmonary shunt in the presence of lung injury. This may have been due to a combination of factors: first, a significant increase in cardiac output with sildenafil in the meconium group and, second, the presence of pulmonary hypertension and parenchymal damage resulting in preexisting ventilation-perfusion mismatch. In addition, increased sympathetic activation resulting in a higher metabolic rate and oxygen consumption may have also resulted from sildenafil administration, as suggested by the investigation of Phillips et al. (15) of sildenafil in healthy humans. We must emphasize that arterial oxygenation is a relatively crude marker of intrapulmonary shunt, and, in the absence of direct shunt measurement, one cannot rule out more subtle effects of sildenafil in our healthy animals.

Schwemmer et al. (16) observed in a study on anesthetized healthy adult dogs a dose-dependent effect of i.v. sildenafil $(0.01-1 \mathrm{mg} / \mathrm{kg} / \mathrm{min})$ on systemic blood pressure and heart rate. In the present study, only minor effects on systemic hemodynamics were observed, consistent with the low doses used $(0.007-0.05 \mathrm{mg} / \mathrm{kg} / \mathrm{min})$. Data from the present study and the previous two studies $(12,13)$ indicate that there seems to be a severe adverse effect when using i.v. sildenafil in animals with lung injury. A marked increase in OI was seen following sildenafil infusion in the meconium aspiration group, which was not seen when given to the animals without lung injury.

In the study by Kleinsasser et al. (14), the intrapulmonary right-to-left shunting of blood was studied by measuring the ventilation/perfusion distribution (V/Q) after enteral administration of sildenafil. They found that any dose of sildenafil increased blood flow to areas with an intrapulmonary shunt, 

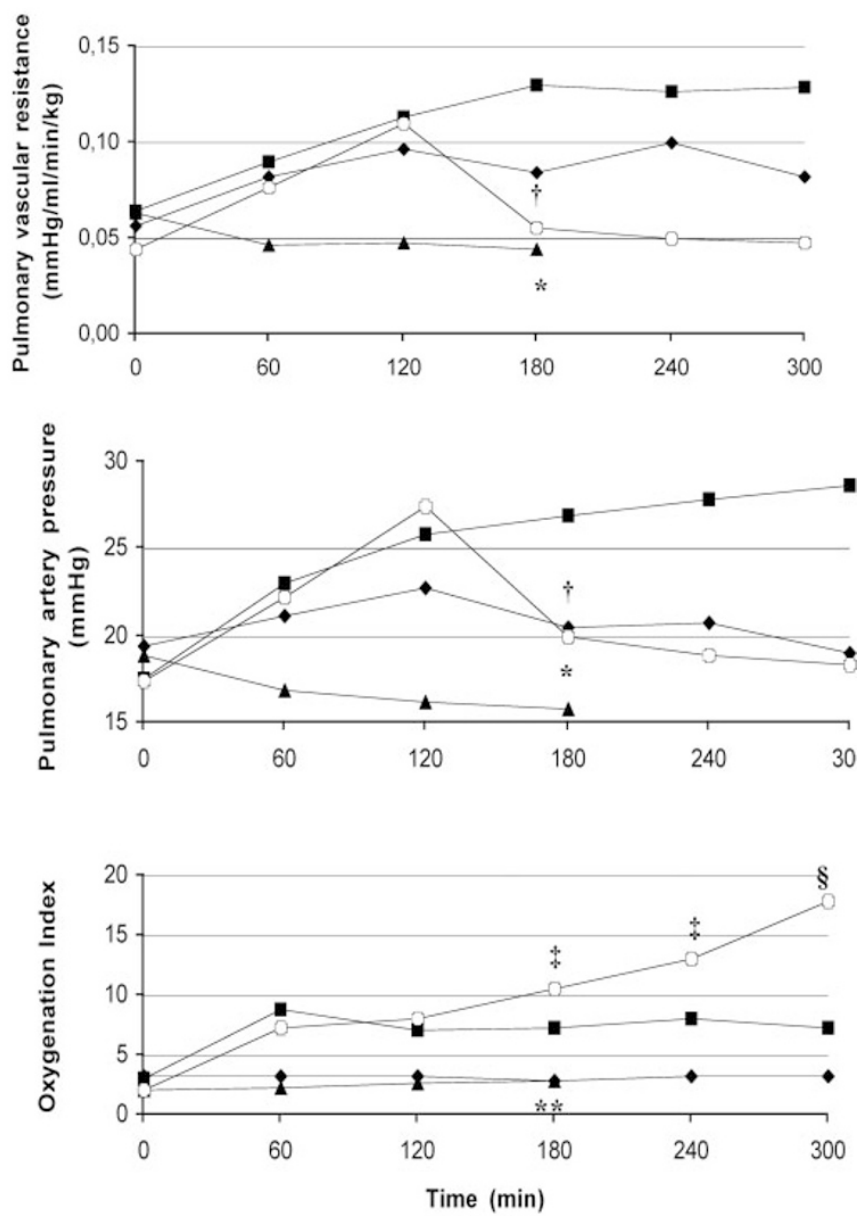

Figure 2. Changes in pulmonary hemodynamics during the study in the anesthesia group $[n=7(\diamond)]$, the sildenafil group $[n=8(\mathbf{\Delta})]$, the meconium group $[n=10(\mathbb{\square})]$, and the meconium + sildenafil group $[n=7(\bigcirc)]$. Graphs represent (starting from the top): changes in PVR $(\mathrm{mm} \mathrm{Hg} / \mathrm{mL} / \mathrm{min} / \mathrm{kg}$ ), changes in mean artery pressure $(\mathrm{mm} \mathrm{Hg})$, changes in OI. ${ }^{*} p<0.01$ in the sildenafil group over time; $* * p<0.001$ in the sildenafil group over time; $\uparrow p$ $<0.001$ in the meconium+sildenafil group compared with $120 \mathrm{~min} ; \ddagger p<$ 0.05 in the meconium + sildenafil group compared with $120 \mathrm{~min}$; $\$ p<0.001$ in the meconium + sildenafil group compared with $120 \mathrm{~min}$.

whereas blood flow to areas with a normal V/Q ratio was reduced.

The animals in this study definitely have areas in the lungs that are poorly ventilated due to the presence of meconium plugs and edema; thus, the severe worsening in oxygenation could be caused by increased blood flow to these areas due to the vasodilating effect of sildenafil. The impairment of oxygenation may be related to the route of administration as no increase in intrapulmonary shunting of blood was found when nebulized sildenafil was administered in lambs with pulmonary hypertension induced by a thromboxane analogue (17).

Intravenous sildenafil seems to have several advantages over the oral drug in the treatment of pulmonary hypertension in newborns. Intravenous sildenafil is easy to administer, and the bioavailability is predictable in critically ill newborns with questionable enteral absorption. However, i.v. sildenafil, unlike inhaled nitric oxide, is not selective to ventilated lung regions. Inhalation therapy with nitric oxide or prostacyclin
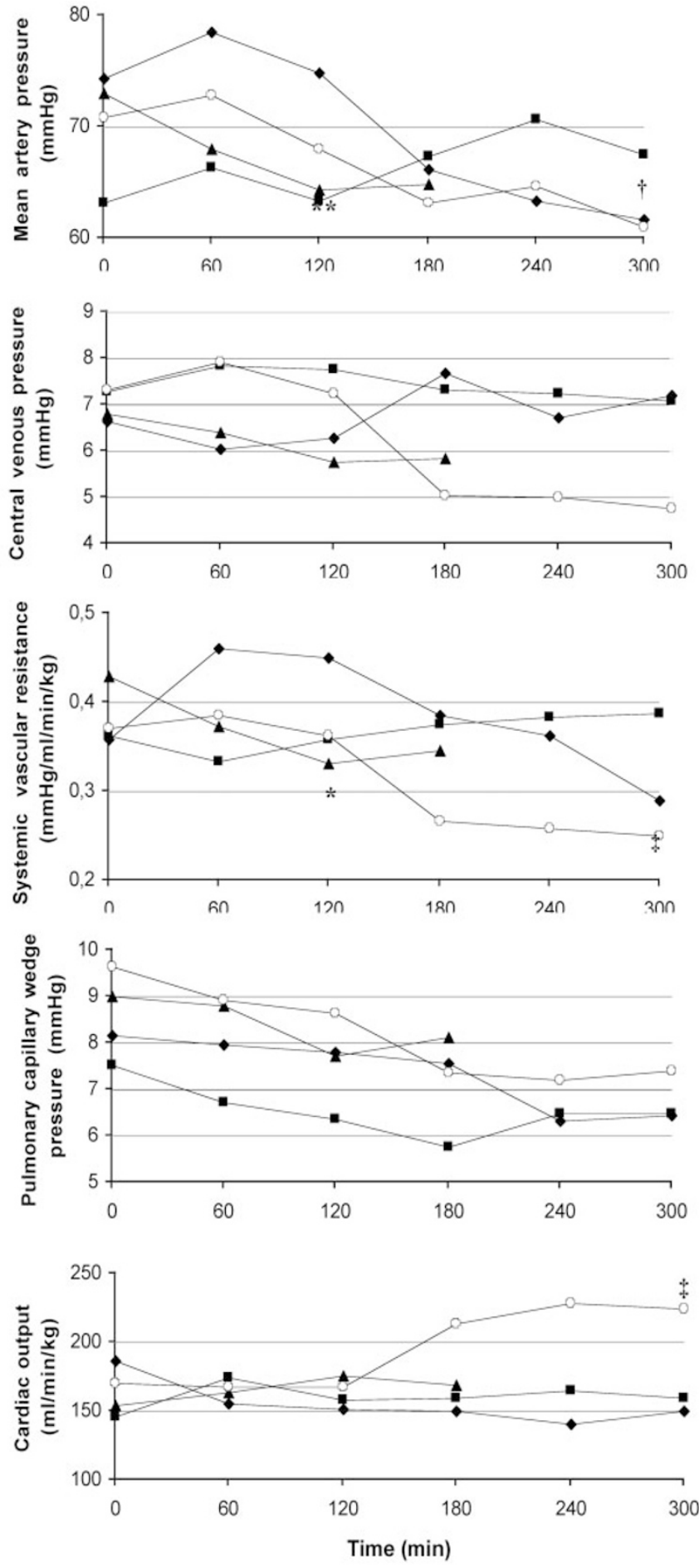

Figure 3. Hemodynamic changes during the study in the anesthesia group $[n=7(\diamond)]$, the sildenafil group $[n=8(\boldsymbol{\Delta})]$, the meconium group $[n=10$ (घ)], and the meconium+sildenafil group $[n=7(\bigcirc)]$. Graphs represent (starting from the top): changes in mean artery pressure ( $\mathrm{mm} \mathrm{Hg}$ ), changes in central venous pressure $(\mathrm{mm} \mathrm{Hg})$; changes in SVR $(\mathrm{mm} \mathrm{Hg} / \mathrm{mL} / \mathrm{min} / \mathrm{kg}$ ), changes in pulmonary capillary wedge pressure $(\mathrm{mm} \mathrm{Hg})$, changes in cardiac output $(\mathrm{mL} / \mathrm{min} / \mathrm{kg}) .{ }^{*} p<0.05$ in the sildenafil group over time; $* * p<0.01$ in the sildenafil group compared with the anesthesia group; $\dagger p<0.05$ in the meconium+sildenafil group compared with baseline; $\ddagger p<0.05$ in the meconium + sildenafil group over time.

primarily dilates the vessels in well-ventilated areas of the lung. This would suggest a possible role for future studies of nebulized sildenafil in our model. 
Some limitations of this study should be mentioned. The sildenafil group without lung injury was only observed for 180 min to obtain a similar time span following sildenafil administration in all groups. However, it might have been interesting to observe the effect of sildenafil on hemodynamics and oxygenation for a prolonged period following cessation of the infusion. We did not determine the maximal duration of the pulmonary vasodilatation following sildenafil, and it is unknown whether the OI would have increased further to critical values. The group of animals without lung injury did not have pulmonary hypertension, so the effect of sildenafil needs to be evaluated in a setup with pulmonary hypertension due to causes other than meconium aspiration. Finally, the lowest dose of sildenafil resulted in a significant reduction in pulmonary pressures and vascular resistance and caused impairment of oxygenation. We cannot rule out that an even lower dose might have been sufficient to obtain significantly improved hemodynamics without any deterioration of oxygenation. These issues need to be addressed in future studies.

\section{CONCLUSION}

Low-dose i.v. sildenafil is an effective pulmonary vasodilator in the presence and absence of pulmonary hypertension secondary to meconium aspiration. However, the agent appeared to be relatively nonselective for the pulmonary vasculature, this dose-related effect being more marked in the lung-injured animals. In animals with meconium aspiration, sildenafil produced a dose-dependent, rapid deterioration in oxygenation.

Intravenous sildenafil should be administered cautiously with the setting of pulmonary hypertension secondary to acute lung injury because of an observed rapid increase in OI.
Acknowledgments. The authors thank the Department of Biostatistics, Aarhus University, Denmark, for statistical assistance.

\section{REFERENCES}

1. Geggel RL, Reid LM 1984 The structural basis of PPHN. Clin Perinatol 11:525-549

2. Kinsella JP, Abman SH 1995 Recent developments in the pathophysiology and treatment of persistent pulmonary hypertension of the newborn. J Pediatr 126:853864

3. Soukka H, Rautanen M, Halkola L, Kero P, Kaapa P 1997 Meconium aspiration induces ARDS-like pulmonary response in lungs of ten-week-old pigs. Pediatr Pulmonol 23:205-211

4. Corbin JD, Francis SH 1999 Cyclic GMP phosphodiesterase-5: target of sildenafil J Biol Chem 274:13729-13732

5. Jackson G, Benjamin N, Jackson N, Allen MJ 1999 Effects of sildenafil citrate on human hemodynamics. Am J Cardiol 83:13C-20C

6. Mychaskiw G, Sachdev V, Heath BJ 2001 Sildenafil (Viagra) facilitates weaning of inhaled nitric oxide following placement of a biventricular-assist device. J Clin Anesth 13:218-220

7. Abrams D, Schulze-Neick I, Magee AG 2000 Sildenafil as a selective pulmonary vasodilator in childhood primary pulmonary hypertension. Heart 84:E4

8. Atz AM, Wessel DL 1999 Sildenafil ameliorates effects of inhaled nitric oxide withdrawal. Anesthesiology 91:307-310

9. Wilkens H, Guth A, Konig J, Forestier N, Cremers B, Hennen B, Bohm M, Sybrecht GW 2001 Effect of inhaled iloprost plus oral sildenafil in patients with primary pulmonary hypertension. Circulation 104:1218-1222

10. Zhao L, Mason NA, Morrell NW, Kojonazarov B, Sadykov A, Maripov A, Mirrakhimov MM, Aldashev A, Wilkins MR 2001 Sildenafil inhibits hypoxia-induced pulmonary hypertension. Circulation 104:424-428

11. Zusman RM, Morales A, Glasser DB, Osterloh IH 1999 Overall cardiovascular profile of sildenafil citrate. Am J Cardiol 83:35C-44C

12. Shekerdemian LS, Ravn HB, Penny DJ 2002 Intravenous sildenafil lowers pulmonary vascular resistance in a model of neonatal pulmonary hypertension. Am J Respir Crit Care Med 165:1098-1102

13. Shekerdemian LS, Ravn HB, Penny DJ 2004 Interaction between inhaled nitric oxide and intravenous sildenafil in a porcine model of meconium aspiration syndrome. Pediatr Res 55:413-418

14. Kleinsasser A, Loeckinger A, Hoermann C, Puehringer F, Mutz N, Bartsch G, Lindner KH 2001 Sildenafil modulates hemodynamics and pulmonary gas exchange. Am J Respir Crit Care Med 163:339-343

15. Phillips BG, Kato M, Pesek CA, Winnicki M, Narkiewicz K, Davison D, Somers VK 2000 Sympathetic activation by sildenafil. Circulation 102:3068-3073

16. Schwemmer M, Bassenge E, Stoeter M, Hartmann B, Hess U, Fink B 2001 Potentiation of sildenafil-induced hypotension is minimal with nitrates generating a radical intermediate. J Cardiovasc Pharmacol 38:149-155

17. Ichinose F, Erana-Garcia J, Hromi J, Raveh Y, Jones R, Krim L, Clark MW, Winkler JD, Bloch KD, Zapol WM 2001 Nebulized sildenafil is a selective pulmonary vasodilator in lambs with acute pulmonary hypertension. Crit Care Med 29:10001005 